\title{
Viejas y nuevas formas de organización campesina en el medio agrario español ${ }^{1}$
}

\author{
Francisco Entrena Durán \\ Universidad de Granada. Facultad de Ciencias Políticas y Sociologia \\ 18071 Granada. Spain
}

\section{Resumen}

Con objeto de determinar la actitud ante lo político-burocrático y la racionalidad formalinstrumental de las que aquí se conceprúan como "viejas" formas de organización campesina, la primera parte del trabajo se centra en el carlismo y el anarquismo, movimientos sociales que pueden ser considerados como las manifestaciones más caracteristicas de las tradicionales formas campesines de organización en España. A medida que se ha ido modernizando la sociedad rural, las "viejas" formas de organización campesina han ido dejando paso a la paulatina instauración y afianzamiento de otras unuevas", de acuerdo con el paradigma burocrático-poítico, en el que, por lo general, se sustentan los sistemas organizativos de las sociedades modernas. Ello trata de ser mostrado a través de la atención que el artículo le presta a las tres organizaciones sindicales a las que, fundamentalmente, están afiliados los trabajadores del campo. Estas organizaciones son: ta Federación de Trabajadores de la Tierra (FTT) de la Unión Gencral de Trabajadores (UGT), las Comisiones Obreras (CC.OO) del Campo y el Sindicato de Obreros del Campo (SOC). A continuación, el trabajo pasa revista y evalúa las aportaciones de tres importantes perspectivas reóricas (Hobsbawm, Wolf y Moore), acerca de las actitudes y potencialidades organizativas del campesinado tradicional. Por último, se concluye con un intento de explicación, por parte del autor, de tales actitudes y potencialidades, a partir de la determinación de algunas de las motivaciones ecosistémicas de las mismas.

Palabras clave: organización campesinado, racionalidad formal-instrumental, paradigmas político-burocráticos, interpretaciones teóricas, ecosistema tradicional rural y acción politica.

Abstract. Old and new forms of rural organization in Spanish agriculture

Wich object of determining the atritude about the political-bureaucractic and the formalinstrumental rationalizy of that which here they are called as "old $n$ forms of rural organi-

1. Agradezco a Eduardo Moyano las fundamentadas observaciones que efecruó al texto originario de este trabajo. Observaciones que, sin duda, han contribuido sustancialmente a su mejora y a una más detallada expliciración de los propósitos del mismo. En cualquier caso, de los errores y carencias que pueda presentar este artículo soy yo el único responsable. 
zation, the first part of the work is centered in the carlism and the anarchism, social movements that can be considerate like the most characteristic manifestations of the traditional rural forms of organization in Spain. While the rural society has gone modernizing, the "oldn forms of rural organization have gone leaving pass to the gradual restoration and strengthening of another "newn, in accordance with the bureaucractic-political paradigm, in what, in general, the organizational systems of the modern societies are sustained. It tries to be shown through the attention that the article dedicates to the three syndical organizations that affiliate, fundamentally, to the spanish rural workers. These organizations are: the Federation of Rural Workers (FTT) of the General Union of Workers (UGT), the Rural Workers Commissions (CC.OO.) and the Syndicate of Rural Workers (SOC). Then, the work overviews and evaluates the contributions of three important theoretical prospects (Hobsbawm, Wolf and Moore), about the atritudes and organizational potentialities of the traditional peaseants. Finally, it is concluded with an intent of explanation, by the author, of such attitudes and potentialities, through the determination of some of the ecosystemic motivations of themselves.

Key words: Peaseants organization, Formal-instrumental rationality, Political-bureaucractic paradigms, Theoretical interpretations, Traditional rural ecosystem and political action.

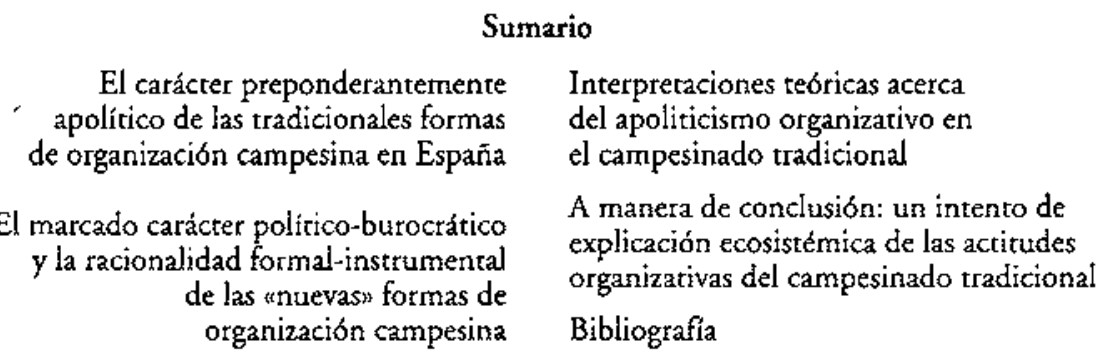

En primer lugar, hay que precisar que los actores sociales campesinos, acerca de los que se habla en el presente trabajo, son los asalariados agrícolas y algunos pequeños propietarios de tierras (especialmente en el caso del carlismo); pues, aunque el tránsito entre las formas organizativas del ámbito rural que aquí se trara de mostrar también puede apreciarse con respecto a los medianos y grandes agricultores, el hecho es que éstos han mostrado siempre en sus formas de organización un cierto nivel de familiaridad y de conocimiento con referencia a los resortes burocrático-políticos.

Independientemente de la racionalidad formal que orienta o legitima (explica, orienta y/o justifica) el establecimiento de sus fines y determina los medios para conseguirlos, las organizaciones constituyen una realidad inestable y dinámica, en la que tienen lugar continuas rearticulaciones y juegos de poder. Una realidad, además, que, dadas sus desigualdades y asimetrías internas, así como complejos procesos concretos de toma de decisiones, dista mucho de ajustarse, en la práctica de su funcionamiento ordinario, a la casi estricta linealidad 
inherente al esquema de racionalidad formal medios-fines que legitima la organización.

No obstante lo que se acaba de decir, la comprensión de dicha racionalidad formal resulta fundamental para entender el funcionamiento de las organizaciones, tomadas éstas en cuenta a nivel global, tal y como se las considera en este trabajo. En él no se pretende afrontar, desde los enfoques que usualmente ha desarrollado la sociología con referencia a ello, el estudio de las organizaciones sindicales de trabajadores rurales tomadas en consideración. Asimismo, lo que, básicamente, se propone el presente artículo no es, tampoco, efectuar una investigación histórica de los movimientos sociales agrarios en él referidos. Tales organizaciones sindicales y movimientos sociales son considerados aquí sólo como un marco histórico-contextual a partir del que mostrar el contraste entre las globalmente conceptuadas como "viejas" y "nuevas" formas de organización campesina. Contraste que refleja como, en el medio agrario tradicional español, han proliferado tipologias de formas organizativas campesinas no sujetas al paradigma moderno de racionalidad formal-instrumental y político-burocrática, en el que tienden a insertarse las actuales modalidades de organización campesina. Estas "viejas» formas de organización campesina, a medida que se ha transformado la sociedad rural (la que ha adoptado, de manera gradual, las pautas del mundo urbano-industrial, a la vez que se ha insertado paulatinamente en la lógica global de éste), han ido dejando paso a la progresiva instauración de "nuevas" formas de organización en la misma acordes con el paradigma en que, por lo general, se sustentan los sistemas organizativos de las sociedades modernas.

Max Weber se preocupó en su obra de determinar las posibles formas de racionalidad que pueden subyacer a la conducta de los actores insertos en la acción social. Acción que puede ser:

1) racional con arreglo a fines, determinada por expectativas en el comportamienro tanto de objetos del mundo exterior como de ottos hombres, y utilizando esas expectativas como "condiciones" o "medios" para el logro de fines propios racionalmente sopesados y perseguidos. 2) racional con arreglo a valores, determinada por la creencia consciente en el valor -ético, estético, religioso o de cualquiera otra forma que se le interprese- propio y absoluto de una determinada conducta, sin relación alguna con el resultado, o sea puramente en méritos de ese valor. 3) afectiva, especialmente emotiva, determinada por afectos y estados sentimentales acruales, y 4) tradicional: determinada por una costumbre arraigada. (Weber: 1979,20 )

En consonancia con la tipología maxweberiana, la racionalidad de las formas de organización conducentes, en la sociedad campesina tradicional española, a la articulación colectiva y/o a la adopción de estrategias de movilización y de acción social, se rige más de acuerdo con valores, afectos o tradiciones que con arreglo a unos fines clara y explícitamente planificados o previstos. Se trata pues de una racionalidad organizativa en la que pesan más los referentes existenciales que conforman la identidad colectiva que el pragmatismo 
instrumental característico de las modalidades de organización preponderantes en las sociedades modernas, en las que existen circunstancias y cauces más apropiados para el surgimiento y desarrollo de formas de organización de índole burocrático-política. Formas de organización que, como consecuencia del proceso de modernización y consiguientemente de urbanización del medio agrario hispano, tienden también a extenderse poco a poco en el ámbito rural.

El rechazo y/o desconocimiento de los campesinos tradicionales españoles con respecto a los referentes burocrático-políticos, algunas de cuyas razones tratan de ser explicadas en este trabajo, no implica, como han creido ver algunos autores, que el campesinado tradicional sea prácticamente incapaz de organizarse por sí mismo, así como de articular proyectos de cambio social con una mínima racionalidad y coherencia organizativas. Lo que sucede es que la coherencia y la racionalidad de las formas organizativas del campesinado tradicional son cualitativamente distintas de sus equivalentes en el contexto moderno-urbano, orientadas éstas por una racionalidad de corte político-burocrático.

\section{El carácter preponderantemente apolítico de las tradicionales formas de organización campesina en España}

Aquí se hace referencia al campesinado español durante el siglo XIX, aglutinado fundamentalmente en torno al carlismo $y$ al sindicalismo anarquista ${ }^{2}$. El carlismo consistió en un movimiento social que se extendió, sobre todo, por la zona norte de España, en la que existía una sociedad rural integrada por pequeños y medianos propietarios, con muy escasa presencia de trabajadores sin tierra (Pérez Yruela: 1990, 220). Las comunidades rurales en esta zona tenían, pues, una estratificación social basada en las diferencias de tamaño y de riqueza de las explotaciones. Estratificación social que no era muy polarizada, dado que dichas diferencias no eran por lo general muy grandes. Por contra, en el sur, área de máxima implantación de los movimientos sociales organizados a través del sindicalismo anarquista, han coexistido, en las comunidades rurales, un número muy reducido de grandes propietarios con una gran cantidad de trabajadores sin tierra. Ello ha dado lugar a un clima fuertemente conflictivo propio de una sociedad de clases. En cualquier caso, tanto el carlismo como el anarquismo son movimientos sociales que no van a constituir por sí mismos objeto de estudio sociohistórico en el presente trabajo, sino que de lo que se trata es de determinar algunas de las razones del carácter preponderantemente apolítico de ambos.

2. En lo que se refiere al cariismo $y$ al anarquismo, aunque existe una abundante bibliografia de ello, se citan aquí para el lector no conocedor del tema las dos obras siguientes: J. Arósregui, M. Blinkhorn, J. M. Torre y M. Fernández (1985), y, Álvarez Junco, José (1976). Ambas incluidas en el repertorio bibliográfica de esre trabajo. 


\section{El carlismo}

En concreto, por lo que se refiere al carlismo, hay que señalar que éste no se entiende, cabalmente, sin tener en cuenta que se trata de algo más que un movimiento social organizado por la Iglesia en connivencia con los poderes más "tenebrosos" del antiguo orden señorial. La perpetuación de esa especie de patrimonialismo tradicional, vigente en el antiguo régimen, postulada por el carlismo frente a los presupuestos organizativos del Estado liberal se explica, en gran medida, como un inrento de propiciar la conservación de los referentes religioso-culturales del mundo tradicional. Referentes que se proponen, de forma más o menos explícita, como el paradigma legitimador de unas reivindicaciones tendentes a salvaguardar el mantenimiento del status socioeconómico de los campesinos. Status amenazado por efecto de la desamortización y de otras medidas político-normativas modernizadoras que, lejos de conducir a la realización de las promesas de mejora generalizada de las condiciones sociales vaticinadas por el reformismo ilustrado orientador de las mismas, resultaron en la práctica sólo efectivas para el afanzamiento organizativo de un moderno Estado centralista de corte liberal. Un Estado que, tras desvincular al campesinado de sus ataduras señoriales, no parecía ofrecer otra alternativa de recambio que dejarlo en el desarraigo y en ta miseria. Ese visceral rechazo de lo moderno y repliegue en una especie de mitriftcación mixtificadora del mundo tradicional, mostrado por los carlistas, suele ser una constante en los movimientos tradicionales campesinos de otros paí$\operatorname{ses}^{3}$. Sucede que los campesinos tratan de aferrarse a los que consideran sus referentes religioso-culturales esenciales para, de esta forma, fortalecer su rechazo a los paradigmas por los que se rige el Estado moderno. Unos paradigmas que no solamente les resultan desconocidos y extraños, sino que también su aplicación supone para ellos una amenaza o experiencia real de empeoramiento de sus condiciones materiales de existencia. Como escribe Julio Aróstegui:

En suma, el carlismo nació como propuesta del "Antiguo Régimen» contra el proyecto de su eliminación. Producto cierto de unas estructuras precapitalistas. Pero es que las nuevas que se pretendian implantar distaban mucho de ser un proyecto común de los diferentes estratos sociales [...]. Si es que tal proyecto era posible y tiene algún sentido. (1985: 8)

3. A este respecto, y con fines meramente ilustrativos, se refieren aquil los dos casos siguientes: el zapatismo, analizado por F. Encrena (1987) en "El papel del campesinado en la Revolución mexicana". Cuademos de Ciencia Política y Sociologia, núm. 19. Colegio Nacional de Doctores y Licenciados en CC. Políticas y Sociología. Madrid, y el movimiento cristero, estudiado por F. Entrena (1986) en "Los levantamientos cristeros en México: entre la "guerra santa" y la reivindicación agrarista". Revista de Indias, núm. 178. Consejo Superior de Invescigaciones Científicas. Madidid. 


\section{Las organizaciones sindicales anarquistas: razones concretas de su fuerte implantacion en nuestro pais}

Autores como Barragán, González y Sevilla sostienen que existe una cierta ambiguiedad en el concepto de socialismo empleado por Juan Díaz del Moral en su clásica Historia de las agitaciones campesinas andaluzas. Asimismo, consideran que, de alguna forma, el anarquismo campesino andaluz presenta rasgos similares a los del movimiento narodnista o populismo tuso del siglo XIX. Tales rasgos suponen una acción social o colectiva del campesinado centrada en:

a) el combate a la mercantilización de sus intercambios, tanto con la naturaleza como con la sociedad a que les fuerza el proceso de privatización que conilleva el avance del capitalismo; b) el escepticismo ante las formas de participación política que acompañan a la democracia formal; c) la presencia en su colectivo de valotes éticos e igualitarios a los que se atribuye una dimensión de ley natural; d) la propiedad colectiva con posesion individual de los tecursos naturales, y e) la autorregulación política local. (1985: 6)

En defrnitiva, en dichos rasgos se pone de manifiesto el caracteristico localismo, oposición al Estado y apoliticismo, cuando no antipoliticismo, del anarquismo rural hispano, que será objeto de estudio a continuación.

Habria que preguntarse el porqué del enorme arraigo popular de la forma de organización anarquista en la sociedad agraria de la España decimonónica. En este sentido, con referencia a la fuerte implantación del bakuninismo en España, José Âlvarez Junco (1976: 588-599), cuyas argumentaciones no sigo exactamente, apunta los tres tipos de explicación siguientes: la económicosocial, la religiosa y la político-institucional.

a) El irregular desarrollo económico-social del país conllevó que coexistieran formas organizativas e ideologías capitalistas avanzadas con supervivencias casi feudales, artesanales y agrícolas, con predominio de las segundas sobre las primeras. El bakuninismo ejerció un fuerte influjo en estos medios, ya que conectó bien con los valores, las simbologías y las inquietudes propias de la existencia del campesinado tradicional, del que adoptó sus ancestrales reivindicaciones y al que supo hablar en su propio idioma, consagrando sus típicas formas de insurrección organizada más o menos espontáneamente. Las promesas bakuninistas constituían la expresión de ideales preindustriales y precapitalistas (a través de ellas se manifestaba la aspiración a instaurar formas de organización similares a las comunitarias medievales, a la autogestión, a la eliminación de toda modalidad de burocracia político-estatal, etc.) que resultaban especialmente atractivos para los habitantes de poblaciones caracterizadas por la autosuficiencia y un casi total aislamiento.

Se explica de este modo el éxito que tuvo el anarquismo en zonas predominantemente agrícolas (tales como Andalucía, Ucrania o el Mezzo- 
giorno), así como la reacción contra los patrones de vida urbanos e industriales manifestada por autores como Proudhon quien, en esta cuestión, se diferencia claramente de, por ejemplo, Marx. Este encomia a la burguesía porque, a su juicio, dicha clase ha urescatado a una parte considerable de la población del cretinismo de la vida rural» (cit. por Álvarez Junco, 1976: 588); asimismo, en unas consideraciones sobre el medio rural francés, muestra que las familias campesinas tradicionales constituyen un reducto de conservadurismo, una especie de "saco de patatas" sin nada en común que les vincule y, por lo tanto, incapaces de organizarse políticamente (El Dieciocho Brumario..., p. 99-100).

Aunque el ideario del «anarquismo nunca rebajó o despreció la importancia de los beneficios logrados por el progreso técnico (tan liberadores como los progresos éticos o filosóficos) y los ideales industriales están generalmente patentes en la que suele Ilamarse utopía anarquista" (Álvarez Junco, 1976: 591), lo cierto es que estos presupuestos quedaron reducidos al plano de lo meramente doctrinal, de la ideología oficial propugnada por los grandes teóricos, líderes o dirigentes. Ideología ésta que, con asiduidad, era contradicha por los comportamientos concretos de las bases sociales sobre las que arraigó el anarquismo. Ejemplos de lo que se está afirmando son las usuales destrucciones de máquinas agrícolas y el rechazo visceral de la mecanización del medio rural que, reiteradamente, tuvieron lugar, a lo largo del siglo XXX y durante las primeras décadas del $\mathrm{XX}$, por parte del campesinado español que, de este modo, trataba a su manera de preservar sus puestos de trabajo. Es así como se explica que en los textos de los anarquistas españoles se aprecien idealizaciones de la agricultura y del supuesto modo de vida puro, natural y comunitario en lo organizacional que diferencia, en opinión de tales textos, la sociedad rural tradicional con respecto a las corrompidas y rechazadas formas de organización burocrático-políticas del mundo urbano-industrial.

El hecho de que el anarquismo arraigara tan fuertemente en una sociedad relativamente industrializada, en el período a que se está haciendo referencia, como la barcelonesa de entonces, puede ser explicado, entre otras razones, por la abundante inmigración campesina que en ella tuvo lugar, así como por el carácter fragmentario y familiar que tenía la industrialización catalana, lo que fomentaba el surgimiento y la proliferación de idearios obreros de carácter autonomista y artesanal. De todos modos, el caso de Barcelona refleja que cualquier forma de desarrollo industrial no implica, necesaria e inevitablemente, el surgimiento de un proletariado industrial de ideología marxista. Análogamente, no existe una especie de correlación invariable entre el auge del anarquismo y la sociedad campesina tradicional; pues, de ser de esta forma, ¿cómo se explica que el anarquismo no se desarrolłara, por ejemplo, en los países escandinavos o anglosajones? Al aludir a la base económico-social agraria, lo que se está tratando de mostrar es que el anarquismo arraigó con tanta fuerza en la sociedad rural española (especialmente, en la andaluza) porque dicha base 
económico-social, por su propia y específica naturaleza, presentaba condiciones muy adecuadas para el surgimiento y desarrollo de la modalidad de organización anarquista, caracterizada por su rechazo a los paradigmas urbano-burocráticos y políticos. Tales condiciones se patentizaban, por ejemplo, en la existencia de grandes masas de marginados y/o de desposeídos como consecuencia de una estructura socio-económica cuyas fuertes desigualdades históticas se habían mantenido intactas, cuando no agudizado, a raíz de la desamortización.

b) En segundo Ittgar, en el rápido y casi repentino proceso de secularización experimentado por la sociedad española durante el siglo XIX, el anarquismo viene a desempeñar para las clases trabajadoras una función equivalente a la que otrora había cumplido la Iglesia (defensora de principios ético-sociales como la igualdad humana esencial, las formas de comunismo primitivo y la solidaridad entre los más humildes de la escala social). Desde otro punto de vista, el anarquismo constituye muchas veces la expresion de una especie de fe, desprovista casi por completo de bases lógico empíricas que la sustenten, una forma de milenarismo profético, laico y racional, según la cual la llegada del comunismo era vista como algo inminente que sobrevendría, prácticamente, de manera espontánea sin que hubiera necesidad de organizarse y de articular y llevar a cabo proyectos programados para conseguirlo. Tampoco se tenía una idea muy precisa respecto a lo que era el comunismo. Con referencia a éste, las fórmulas libertarias, inconcretas de por sí, llegaron a las masas con un nivel de vaguedad y de imprecisión tales que hacían posible todo tipo de interpretaciones.

En el planeta existen acumuladas riquezas infinitas que, sin su monopolio, asegurarian la felicidad de todos los humanos. Todos tenemos derecho al bienestar, y cuando rija la anarquía cada cual tomará del acervo común cuanto necesite; los hombres, sin distinción, serán dichosos; el amor será la única ley de las relaciones sociales. ¿Como conseguir esto? Acabando con la autoridad y con la propicdad, bases de la desigualdad y únicas fuentes del mal y de la injusticia; organizando la producción mediante el libre acuerdo de los individuos y de los grupos, que se juntarán según afinidades naturales. (cit. por Dlaz del Moral, 1979: 198)

La profecía estaba pues bien clara, pero lo referente a la manera de organizar la producción en la futura sociedad comunista no era bien entendido ni estaba previsto por aquellas gentes. Y como se consideraba que la revolución social sobrevendría de un momento a otro, los buenos campesinos idearon una organización de la producción agrícola, que no era más que la expresión mitificada de su vehemente anhelo de siempre: el reparto de la tierra, o sea, una especie de nueva y más equitativa desamortización. 


\begin{abstract}
¿No se trataba de conseguir la felicidad de todos y que todos fueran iguales? ¿No era la posesión de la tierra el medio de que disponían los burgueses para disfrutar y ser dichosos? Pues, evidentemente, los trabajadores también lo serían cuando dispusieran de su suerte de tierra como disponian de suazada. jLa cantidad de tierra monopolizada era enorme! ¡Había para todos, hasta para los burgueses! Esta creencia en el reparco se hizo general en las masas. (Díaz del Moral, 1979: 199)
\end{abstract}

Los obreros y/o los lídetes más cultos tenian una visión algo más elaborada de lo que era el comunismo, pero como no podían ofrecer alternativas convincentes y precisas frente a las soluciones claras y diáfanas inventadas por la multitud, no ponian mucho énfasis en modificar la creencia tan fuertemente asentada en la generalidad de la población, pues, como acertadamente se pregunta Díaz del Moral, "chubieran logrado arrastrar a las muchedumbres unánimes, contrarrestando sus ilusiones?" (1979: 199).

El creciente rechazo del catolicismo, a raíz del proceso de secularización en el que tenía lugar la paulatina implantación del anarquismo, era reemplazado por la visión profética del porvenir y la rígida moral laica (orientadas éstas por un fervor tan fuerte o más que el de estricta naturaleza religiosa) inherentes a la ideología y a los presupuestos teóricos de dicha forma de organización y de movilización social, que con tanta fuerza arraigó en la sociedad campesina tradicional española. Tanto las autoridades como las clases acomodadas, considerando al anarquismo andaluz a través de las referencias que tenían del extranjero y del terrorismo catalán, vefan a los centros obreros anarquistas como antros en los que se tramaban tenebrosas conjuras y en los que se urdian complejos y misteriosos procedimientos para degollar a los ricos y derrumbar los pilares deł orden social. Presuposición completamente alejada de la verdad, pues, por lo general, la vida de aquellas organizaciones de trabajadores y sus comportamientos eran de una sencillez, autenticidad moral y transparencia absolutas. Vida modélica esperanzada en que estaba muy pronta la revolución social y el consiguiente reparto de la tierra en lores individualizados para cada familia, así como la inmediata llegada de la «buena nueva» anunciada por los maestros de esta doctrina laica, cuyos libros aseguraban:

que las riquezas de la humanidad eran tales que hacían posible el bienestar de todos y que cuando se implancara la anarquía, una vez eliminados los motivos del mal y de la discordia, los hombres todos, burgueses y trabajadores, vivirán felices, sin más ley que el amor y la fraternidad. Y como los buenos campesinos esperaban de un día a otro el advenimiento del anhelado régimen, algunos de ellos, almas ingenuas y sin recodos, llegaron a pensar que hasta los ricos escarían conformes con los pobres y no opondrían dificulcades a su triunfo. (Díaz del Moral, 1979: 201) 
c) En el plano político-institucional es patente la decepción de los campesinos ante la Administración española decimonónica caracterizada por la corrupción, la imprevisibilidad de los continuos golpes de Estado y pronunciamientos militares, así como por la ineficacia a la hora de resolver las preocupaciones cotidianas más inmediatas de la población. Así, el rechazo a la política característico del anarquismo hispano es una muestra de la oposición a los paradigmas burocrático-organizativos del Estado liberal por parte de una población para la que el proceso de centralización de dicho Estado había conllevado, fundamentalmente, un grave empeoramiento de sus condiciones de vida. Con referencia al rechazo de lo político, Juan Díaz del Moral escribe lo siguiente:

Existía entonces [...] en toda Espańa una extensa corriente de opinión, común a todas las clases sociales, que consideraba a la política como una actividad amoral, de orden inferior, cuyos temas y motivos tutilizan sus profesionales para medrar, para crearse una posición y para justificar toda suerte de desmanes y de bellaquerías. Ha quedado como frase hecha la que condensa esta general creencia: "La política todo lo corrompe». Y para avalorar una entidad $y$ atraer a las gentes se afirmaba que era completamente "ajena a la política». $Y$ como la literatura y los agitadores anarquistas reproducian estas opiniones, corroboradas por el dogma de su credo de que todo poder y autoridad engendran necesariamente la injusticia, las propagandas encontraron fácil eco en las muchedumbres. (1979: 197-198)

\section{El marcado carácter político-burocrático y la racionalidad} formal-instrumental de las "nuevas» formas de organización campesina

Tras la restauración de la democracia en España (en 1975) y la recuperación de la libertad de asociación que ello supuso, se inició un proceso de reorganización en el medio agrario, que aún continúa, en el que, aparte de la dispersión organizativa existente, se ha puesto de manifiesto, entre otros aspectos, la heterogeneidad de la estrıctura social agraria de nuestro país (Pérez Yruela, 1990: 224 y s.). Las asociaciones de tipo reivindicativo, a través de las cuales se lleva a cabo la representación de intereses en la agricultura, pueden ser conceptualizadas, en general, como "sindicatos». No obstante, según el grupo de interés que tales organizaciones representan, suelen recibir distintas denominaciones (Moyano, 1992: 1). Así, por ejemplo, son denominadas como Organizaciones Profesionales Agrarias (OPAS) aquellas que representan los intereses de los agricultores, independientemente del tamaño y de las orientaciones productivas dadas a sus explotaciones, mientras que, si se trata de asalariados agrícolas el grupo a representar, entonces tales organizaciones reciben el nombre de Sindicatos Obreros Agrícolas. De éstos se ocupa el presente epigrafe.

A nivel nacional, los trabajadores asalariados rurales están sindicados, en su mayoría a las Comisiones Obreras del Campo (CC.OO.) y, en menor medida, a la Federación de Trabajadores de la Tierra (FTT) de la UGT. En Andalucía 
hay que referenciar, adernás, al Sindicato de Obreros del Campo (SOC) de implantación muy localizada en una restringida área de las provincias de Sevilla y de Cádiz

En contraste con las formas de organización típicas del campesinado medio rural tradicional, las dos primeras organizaciones sindicales de ámbito nacional, a las que en la actualidad están afiliados fundamentalmente los trabajadores agrícolas, presentan, en lo que se refiere a su estructura interna, funcionamiento y papeles que desempeñan, las características propias de las organizaciones formales que, en definitiva, son. Ello significa que tales sindicatos funcionan con arreglo al esquema de racionalidad formal medios-fines antes referido.

El autor es consciente de que esta concepción, focalizada en la mera consideración de la racionalidad formal de los actuales sindicatos españoles (aquí considerados como arquetipos de las "nuevas" formas de organización campesina), implica una abstracción que, en alguna medida, conlleva la percepción de tales organizaciones como entidades individuales con una racionalidad propia claramente definida, lo que, inevitablemente, simplifica (o no considera suficientemente) la compleja y contradictoria dinámica interactiva (generalmente imprevisible) de las organizaciones, que suelen estar integradas por conjuntos más o menos numerosos y variados de sujetos y grupos que ocupan en ellas diferentes $y / o$ desiguales posiciones y tienen distintas opiniones y puntos de vista. De todas formas, hay que subrayar que el hecho de centrarse en la mera consideración del criterio formal de racionalidad es bastante útil para efectuar una aproximación al marco que legitima (explica, orienta y/o justifica) el funcionamiento y las estrategias de acción de la organización, concebida ésta desde una perspectiva global, tal y como se viene haciendo en el presente trabajo con referencia a las formas organizativas del campesinado hispano.

Consideradas globalmente, las actuales organizaciones sindicales españolas tienden a funcionar como si fueran entidades individualizadas, cuyo criterio formal de racionalidad legitimadora es equiparable, en cierto modo, al del individualismo metodológico característico del paradigma de la teoría de la elección racional. Dicho de otra manera, tales sindicatos tienden a desenvolverse, al menos en el plano formal, cual si fueran actores individuales racionales que buscan la forma más effcaz de usar los medios de que disponen de cara a maximizar los resultados inherentes a los fines que tratan de conseguir. $\mathrm{Y}$ que los sindicatos se conducen como entidades individuales significa que, en cierto modo, puede presuponerse que, al igual que las personas concretas, "actúan intencionadamente en la persecución de una meta, meta que (lo mismo que las acciones) está condicionada por los valores o preferencias" (Coleman, 1990: 13).

4. Un estudio más detaliado de esta organización campesina, por parte del autor, es F. Entrena (1994 b). 
A diferencia de lo que sucede con organizaciones sindicales como la FT'T y las CC.OO. del Campo, el SOC, aparte de que manifiesta algunos de los rasgos propios del anarquismo decimonónico, ha funcionado más de acuerdo con las pautas peculiares de un movimiento social que con las de una organización formal. Ello no quiere decir que dicho sindicaro se encuentra completamente al margen de la racionalidad formal-instrumental mediosfines. De hecho, se observa en él una tendencia gradual a ir insertándose en las pautas de dicha racionalidad, la cual, en este caso, se materializa a través de la actuación del SOC como un movimiento social característicamente moderno, cuya actuación sociopolítica transcurre, en gran medida, de acuerdo con el proceso conducente a una acción colectiva eficaz desarrollada por Charles Tilly en su teoría de la protesta. En efecto, aparte de su utilidad para explicar el desenvolvimiento de la violencia revolucionaria, la aportación de Tilly también puede resultar adecuada para la explicación de aquellas acciones colectivas concretas de protesta y de reivindicación que, usualmente, tienen lugar en el marco de los cauces institucionalizados existentes en el seno de los sistemas sociales democráticos modernos. Según dicho autor, la acción colectiva eficaz conlleva las cuatro fases siguientes: organización del grupo o grupos implicados, movilización, percepción de los intereses comunes y aprovechamiento de las oportunidades concretas para actuar eficazmente (Tilly, 1978: 7-10). En este sentido, a diferencia del espontaneismo que frecuentemente caracterizó a los levantamientos anarquistas, las movilizaciones del SOC evidencian un cierto nivel de organización y de planificación de las mismas, pues se suelen desarrollar buscando la oportunidad más propicia para obtener un mayor eco en la opinión pública y eficacia, en lo que respecta a aprovechar más eficientemente los medios de que se dispone para conseguir los fines buscados.

La radicalidad de los planteamientos de este sindicato evidencia, entre otras cuestiones, una expresión de la inquietud manifestada por la abundante población jornalera, existente en el área de implantación del mismo, ante su irremisible desplazamiento del ámbito productivo agrario, como consecuencia de la progresiva inserción del mundo rural en la lógica de la economía de mercado y de la consiguiente modernización que eilo conlleva. En la medida en que emerjan y se afiancen alternativas de recualificación profesional y de reubicación social y laboral de estos jornaleros, es posible que, poco a poco, vayan arraigando entre ellos actitudes menos radicales y más reformistas, tal y corno ya sucede entre la población asalariada agricola de otros paises europeos y, en líneas generales, con la afiliada a los otros dos sindicatos del campo español.

En cualquier caso, independientemente del mayor o menor nivel de radicalidad de sus discursos ideológicos, lo que interesa destacar, para los fines de este trabajo, es que las tres organizaciones sindicales antes mencionadas funcionan como instrumentos de mediación entre el Estado y la sociedad y participan, aunque en mayor medida las dos primeras, de las pautas de racionalidad formal-instrumental y de la modalidad de acción social inherente a la política, 
características de las sociedades avanzadas actuales (Entrena, 1994a). En ellas el mundo rural se encuentra cada vez más inserto en el contexto global a nivel económico, cultural e institucional, a raíz del paulatino proceso de modernización del agro. Proceso éste en el que incluso han desempeñado una considerable influencia las estrategias movilizadoras y funciones desempeñadas por los sindicatos agrarios que, lejos del usual carácter globalizante y general de sus reivindicaciones clásicas, tienden cada vez más a dejarse llevar por el consejo de técnicos y expertos, integrados en sus filas y en continuo incremento de su proporción e influencia en ellas, que les asesoran en las acciones concretas que deben emprender para lograr los fines específicos que en cada caso se proponen conseguir.

Especialmente, las Comisiones Obreras del Campo y la Federación de Trabajadores de la Tierra de la UGT son organizaciones sindicales campesinas que pueden ser consideradas como auténticos prototipos de organizaciones formales racionales, en lo que a su estructura interna, estrategias de acción, funcionamiento y papeles desempeñados se refiere. Decir que dichos sindicatos son organizaciones formales significa que éstos son asociaciones que funcionan de acuerdo con el establecimiento de unas reglas que rigen las actividades $y$ las posiciones ocupadas por sus miembros $y$, asimismo, poseen una estructura jerárquica y un programa de objetivos formales y de medios para materializar tales objetivos (De la Fuente, 1991: 15).

Por lo que respecta al SOC, éste constituye un caso atípico, de tal forma que, a partir de un análisis de contenido de los textos publicados por dicho sindicatos, se muestra como éste es el prototipo de una organización campesina característica de una sociedad rural en crisis de modernización. En este sentido, junto a la actitud negativa ante lo político-burocrático, al asamblearismo, al utopismo, a la intachable moralidad propugnada en sus escritos o manifestada por sus dirigentes y a otras características análogas a las del anarquismo de la sociedad campesina tradicional, aunque en el SOC prosigue vigente esa mitificación del reparto de la tierra típica de las agitaciones campesinas decimonónicas a la que se refiere Díaz del Moral, se manifresta, también, en esta organización una cierta preocupación por fundamentar racional y/o técnicamente sus reivindicaciones de reforma agraria, de desarrollo rural y de nivelación general de la estructura social. Se patentiza, así, la gradual evolución del SOC hacia su relativa insercićn en los paradigmas de acción formal-instrumental y político-burocrática.

En definitiva, en las tres organizaciones sindicales a las que se acaba de hacer referencia se observa un proceso de afianzamiento progresivo de la racionalidad formal-instrumental inherente a las "nuevas" formas de organización de la sociedad moderna en genexal, de las que cada vez participa más el mundo rural de paises industriales relativamente avanzados como España. Mundo

5. El material analizado (véase la bibliografia reseñada al final de este trabajo) corresponde a finales de los serenta y a los primeros años de la década de los ochenta, período de mayor dinamismo e inzensidad movilizadora de esta organización reivindicativa. 
rural que constituye un ámbito perfectamente integrado económica, social e institucionalmente en la globalidad de dicha sociedad, de la que ya sólo se diferencia básica y únicamente por su particular especialización productiva de naturaleza agraria.

\section{Interpretaciones teóricas acerca del apoliticismo organizativo en el campesinado tradicional}

Una vez establecido el contraste entre las "viejas" y "nuevas" formas de organización rural en España, las páginas siguientes del trabajo tratan de ahondar en las interpretaciones teóricas, elaboradas por parte de tres clásicos estudiosos del campesinado, con respecto a ese característico rechazo del mundo agrario tradicional a los paradigmas organizativos modernos. Aparte de las referidas motivaciones concretas que repercutieron en el apoliticismo de los campesinos tradicionales españoles y en la opción de éstos por el anarquismo, hay que aducir también razones de índole general aplicables al campesinado tradicional en su conjunto. En este sentido, a la vez que se hace referencia críticamente a las aportaciones de Eric. J. Hobsbawm, Eric R. Wolf y Barrington Moore, se trata aquí de utilizar las argumentaciones de estos autores para articular, a partir de un seguimiento no estrictamente literal de las mismas (que, sin embargo, trata de atenerse a las consecuencias que implícitamente subyacen a elias), unas reflexiones acerca de la situación y las capacidades organizativas de la sociedad campesina tradicional.

1. Hobsbawm. Inserto en la tradición teórica marxista, este autor tiende a minusvalorar el papel que puede desempeñar el campesinado tradicional en lo relativo a articular o desenvolverse en organizaciones de carácter político-burocrático. En su conocida obra Rebeldes primitivos (1974) Hobsbawm estudia las que él considera como modalidades "primitivas" o "arcaicas" de organización y de movilización social. Se trata de formas de protesta que tienen lugar en el seno de aquellos grupos sociales, cuyos componentes todavía no se encuentran incluidos por completo en el mundo capitalista urbano-industrial. Los miembros de tales grupos sociales son considerados por el autor como "gentes prepolíticas" que aún no han encontrado o acaban de encontrar unn lenguaje específico en el que expresar sus aspiraciones tocantes al mundon (1974: 11). Por ello, sus movimientos organizativos participan, muchas veces, "de la ceguera y de la inseguridad" (sic) típicas del ámbito en el que se desenvuelven, caracterizado por el analfabetismo y la ausencia de una trayecroria organizativa racional como, por ejemplo, la del sindicalismo moderno de las sociedades industriales capitalistas, en las que preponderan los paradigmas político-burocráticos.

Hobsbawm otorga un lugar bastante destacado al fenómeno del bandolerismo social. Fenomeno que, según este autor, coexiste con movimientos de insurrección social más ambiciosos (lo que lleva a pensar que, necesariamente, éstos estarán mejor organizados) y es relacionado por él 
con la existencia de una situación de descontento social. El bandolerismo social está fundamentalmente integrado por grupos relativamente reducidos de hombres que viven al margen de la sociedad campesina tradicional y cuyas actividiades son vistas como criminales por parte de la estructura de poder oficial y del sistema de valores establecido, pero no (pese a que en ciertas ocasiones puedan existir fuertes reservas al respecto) por el campesinado (Hobsbawm, 1978: 193 y s.). Es esta especial relación que se establece entre el campesino y el bandido la que posibilita que el bandolerismo sea "social»: el bandido social es visto como un héroe, un campeón, un hombre enfrentado a los mismos enemigos que el campesino. Un héroe, cuyas actividades se considera que luchan contra la injusticia, la opresión y la explotación experimentadas por los habitantes del medio rural. El bandido social no es percibido como un criminal por parte de la población campesina, ya que, desde el punto de vista de ésta, no transgrede las reglas que la organización social rural tradicional, en la que tienen lugar las actuaciones de aquél, acepta como morales. Reglas que, por lo tanto, suelen ser, no sólo distintas, sino incluso contradictorias con respecto a las del orden estatal (y por consiguiente organizado según paradigmas político-burocráticos) a cuyas intromisiones y alteraciones de su siruación se opone la sociedad rural, en defensa de su statu quo, y contra el que se enfrenta el bandido social, de ahí la identificación de la primera con éste.

En cualquier caso, desde el punto de vista de las formas de organización de la sociedad campesina tradicional, lo que interesa destacar es que, en opinión de Hobsbawm, $\mathrm{el}$ bandolerismo social constituye la expresión de un modo de protesta social primitiva y no revolucionatia, ya que "carece prácticamente de organización y de ideología y resulta por completo inadaptable a los movimientos sociales modernos" (1974: 15). Una modalidad de protesta, cuya primaria forma de organización, según el entender del autor, la hace susceptible de ser etiquetada por él como una mera "rebelión». En este sentido, puede afirmarse que en Hobsbawm está implícita la clásica distinción académica entre "revolución" y "rebelión". Bajo dicha distinción subyace, a mi juicio, una pretensión de oponer la paradigmática organización racional, que él confiere a las sociedades modernas (insertas en el ámbito de lo político), a la asistematicidad e irracionalidad que, más o menos implícitamente, presupone a las sociedades campesinas tradicionales, consideradas por él como "prepolíticas".

Los anteriores comentarios no pretenden en absoluto disminuir la, sin duda relevante, trascendencia teórica de la aportación de Hobsbawm. Mi propósito es resaltar que, aún cuando los escritos de éste pueden resultar bastante esclarecedores, en lo relativo a comprender algunas de las razones del tradicional apoliticismo y pasividad de los campesinos, así como la dificultad de organizarse de éstos de acuerdo con los presupuestos políticoburocráticos, tales escritos, no obstante, parecen manifestar la existencia en Hobsbawm de una desmedida seducción por los paradigmas organiza- 
tivos de la razón urbano-industrial moderna, en los que, de una u otra forma, se encuentra inmerso el mundo occidental del que forma parte dicho autor. Esta circunstancia le impide a Hobsbawm captar a fondo la indudable capacidad organizativa y simbólica de las sociedades tradicionales, así como el papel que, eventualmente, éstas, en su relación dialéctica con el ámbito urbano-industrial, pueden desempeñar en la planificación y organización de las estrategias inherentes a los procesos revolucionarios y/o modernizadores.

2. Wolf. Hace referencia, también, al usual apoliticismo que impregña las organizaciones tradicionales de los campesinos. Ello se manifiesta, por ejemplo, cuando señala que los mismos utienen desventajas especiales al pasar del reconocimiento pasivo de las injusticias a la participación política como un medio de corregirlas" (1979: 237). Entre las motivaciones de esa pasividad campesina señala Wolf las siguientes: a) el trabajo campesino se efectúa a menudo a solas en su propia tierra, lo que no favorece la aparición o reafirmación de formas organizativas tendentes a reforzar los vínculos de solidaridad; b) los trabajos campesinos constituyen unas rutiras cíclicas que han de ajustarse a la tiranía del tiempo en el que han de llevarse a cabo, sin que puedan ser aplazadas para cuando convenga en razón del interés de planificar y organizar eficazmente la lucha revolucionaria; c) el control de la tierra (téngase en cuenta que Wolf está hablando de una clase de propietarios, en cierto modo, equivalente a la conceptuada por Marx como "saco de pataras") le permite al campesino refugiarse en una economía de subsistencia, que lo sitúa al margen de las consecuencias extremadamente adversas que puede acarrear para su explotación la inserción de la misma en las relaciones de mercado; d) los vínculos de familia extensa y la costumbre del auxilio mutuo dentro de la comunidad contribuyen a amortiguar los golpes de la dislocación que acarrea la penetración de las relaciones de mercado en la organización de la sociedad campesina tradicional; e) las relaciones entre los miembros de la sociedad campesina trascienden, a menudo, las fronteras de clase, de tal forma que, por ejemplo, un campesino rico y otro pobre pueden ser parientes y, por lo tanto, es posible que se produzca entre ellos una cierta "convergencia de intereses", lo que, evidentemente, repercute en las modalidades de organización que en este contexto se generan; f) finalmente, la exclusión del campesinado de la toma de aquellas decisiones que tienen lugar más allá del entorno de su pequeña comunidad, tiende a propiciar en este sector socio-poblacional una visión localista, en lo que respecta al planteamiento de sus problemas y a la manera en que se organizan y/o articulan sus intereses. En consecuencia, concluye Wolf, "los campesinos son a menudo meros espectadores pasivos de las luchas políticas o suspiran por $\mathrm{el}$ advenimiento repentino de un salvador" (1979: 238).

A pesar de las limitaciones de los campesinos para organizarse políticamente, Wolf constata que, en el curso del siglo XX, aquéllos han apoya- 
do la organización y el desenvolvimiento de seis grandes levantamientos sociales y políticos que han sacudido al mundo. Se trata de la revolución mexicana de 1910-1917; las revoluciones rusas de 1905 a 1917; la revolución china, que experimentó varias etapas a partir de 1921; la revolución vietnamita, que tuvo sus raíces en la Segunda Guerra Mundial; la rebelión argelina de 1954, y la revolución cubana de 1958. Todas estas revoluciones se basaron en una considerable participación de las poblaciones rurales en sus cuadros y estrategias organizativas.

La perspectiva antropológica de la que parre Wolf le permite una comprensión más rica de las capacidades organizativas (así como de la complejidad y diversidad de éstas) de la sociedad campesina tradicional. Se trata de un enfoque menos simplificador que el efectuado por Hobsbawm desde su etnocentrismo urbano-industrial moderno. En este sentido, la sociedad campesina tradicional constituye, para Wolf, una entidad organizativa propia con una estructura económico-social y unas vinculaciones relacionales específicas. Ello no implica que el autor no se preocupe de mostrar como la organización de dicha sociedad se halla inserta en un proceso de relación dialectica con la de la sociedad global, de tal modo que las transformaciones en ésta revierten en una alteración general de los pilares organizativos que sustentan la sociedad agraria tradicional.

Con respecto a la articulación propugnada por Wolf de los problemas y de la evolución de la comunidad local campesina en el marco de la sociedad global, tiene especial importancia el papel conferido por el autor al efecto dislocador que, sobre la organización de dicha comunidad local, puede tener la introducción en ella de las relaciones sociales modernas, capitalistas, industriales y de mercado. Las profundas alteraciones, que sobre la comunidad local campesina pueden resultar de tal efecto dislocador, se reflejan a nivel de la organización económico-productiva, así como en lo ecológico y en lo político-instirucional. De esta forma, a nivel económico, suelen incrementarse los despojos de tierras a los pequeños y medianos propietarios campesinos por parte de los grandes terratenientes; en lo ecológico, las comunidades se ven, frecuentemente, privadas, a raíz de ello, de su acceso a recursos básicos para su supervivencia como el agua, los pastos o los bosques; finalmente, en el plano de la organización político-institucional, las tradicionales relaciones de autoridad se ven profundamente alteradas como consecuencia de la irrupción del mercado, a la vez que comienzan a rearticularse otro tipo de relaciones en este sentido.

Todas estas alteraciones, sobre su entorno local, pueden repercutir en que se exacerbe la tradicional condición pasiva del campesinado y en que éste acabe, más o menos consciente de su función, por decidirse a desempeñar un papel activo en la articulación u organización de procesos revolucionarios y/o de modernización tendentes, al fin y al cabo, a instaurar formas organizativas orientadas por los paradigmas burocrático-políticos. En cualquier caso, cuando los campesinos se deciden a tomar parte en la revo- 
lución suele existir una acumulación de factores tal que hace que aquélla se encuentre ya a punto de estallar.

Las rebeliones campesinas del siglo $\mathrm{xX}[\ldots]$ son tas reacciones locales ante los grandes dislocamientos sociales, puestas en movimiento por el cambio aplastante de la sociedad. La expansión del mercado ha descruido las raíces de los hombres, y los ha arrancado de las relaciones sociales en que nacieron. La industrialización y el avance de la comunicación han originado nuevos agrupamientos sociales, todavía inseguros de sus propias posiciones e intereses sociales, pero obligados por el desequilibrio mismo de sus vidas a buscar un nuevo ajuste. La autoridad política tradicional se ha minado o derrumbado; nuevos contendientes pox el poder están buscando nuevos seguidores para entrar en la arena política vacante. Asi, cuando el protagonista campesino prende la antorcha de la rebelión, el edificio de la sociedad está ya humeando y listo para arder. (Wolf, 1979:245)

3. Barrington Moore. En una obra clásica, titulada Los origenes sociales de la dictadura y de la democracia (1976), Barrington Moore trata, entre otros aspectos, de explicar las diferentes funciones políticas desempeñadas por las clases superiores terratenientes y el campesinado en la transformación de las sociedades agrarias (éstas son definidas simplemente como sistemas en los que una gran parte de la población vive de la tierra) en sociedades industriales modernas. En su libro, Moore hace referencia a los casos de Estados Unidos, Francia e Inglaterra (las denominadas clásicamente revoluciones burguesas), Alemania y Japón (caracterizadas por un débil impulso burgués y por revoluciones modernizadoras organizadas y llevadas a cabo desde arriba), Rusia y China (en las que la existencia de grandes organizaciones burocráticas agrarias obstaculizaba el impulso hacia la modernización).

Especialmente, Moore trata de determinar, en cada uno de los casos que contempla en su estudio, las respectivas posiciones ocupadas por los sectores tradicionales agrarios, así como la específica gama de condiciones históricas, mediante las que alguno de los grupos componentes básicos de dichos sectores (es decir, los grandes terrarenientes o los campesinos) acaban por convertirse en fuerzas importantes de cara a la emergencia de modalidades de organización polírico-institucional como las parlamentarias occidentales democráticas o las dictaduras de derechas o de izquierdas, a saber: los regímenes fascistas o comunistas.

En cualquier caso, lo que, desde el punto de vista de este tema, interesa destacar de Moore (aún cuando hay que precisar que éste no se ocupa explícitamente de los cambios en el aspecto organizativo inherentes a los procesos de modernización) es que, según se desprende de los análisis y presupuestos teóricos de su obra, hay que tener presentes los aportes que pueden realizar a la instauración de las formas de organización características de las sociedades modernas las propias clases de las sociedades tradicionales campesinas en descomposición. Subyace a este planteamiento analítico una discrepancia con respecto a los clásicos enfoques dicotómi- 
cos, que han presentado la modernización como el resultado del enfrentamiento entre la "progresista" burguesía urbana y las "reaccionarias" clases de la sociedad campesina tradicional, incapaces por sí mismas de organizarse políticamente y de entender los entresijos de la razón urbano-burocrática. De acuerdo con dichos enfoques, la burguesía por sí sola sería, básicamente, la clase protagonista en la organización y control de los procesos que han dado lugar a las radicales transformaciones consustanciales a la irrupción de la modernidad.

Una vez considerado el papel desempeñado por las clases agrarias tradicionales en la planificación y organización de las diferentes revoluciones y procesos modernizadores, Barrington Moore muestra que dichas clases han influenciado notablemente, cuando no condicionado, los resultados de la modernización y de la consiguiente instauración de los paradigmas organizativos racional-burocráticos y/o políticos. En diversas ocasiones, los sectores tradicionales han constituido el substrato productivo, institucional e ideológico a partir del cual se ha articulado y organizado la construcción de la «nueva sociedad» moderna, y, de este modo, han desempeñado una labor decisiva en la dinámica modernizadora. Ello, bien mediante el protagonismo directo, o indirectamente, a través de alianzas entre las débiles clases medias urbanas insatisfechas de su status y los campesinos descontentos. Sin embargo, conviene precisar que, frecuentemente en estos casos, los campesinos han proporcionado la dinamita para volar el viejo edificio, pero "a las obras de reconstrucción subsiguientes, no han aportado nada; de hecho han sido sus primeras víctimas" (Moore, 1976: 387). En tales circunstancias, los beneficiarios fueron los elementos de las burguesías urbanas, en mejores condiciones socioeconómicas e intelectuales para organizarse y articular las estrategias de acción social racional instrumental, así como los programas político-burocráticos necesarios para materializar la modernización y/o la construcción del Estado.

\section{A manera de conclusión: un intento de explicación ecosistémica de las actitudes organizativas del campesinado tradicional}

En primer lugar, hay que precisar que, al plantear una explicación ecosistémica de la actitud del campesinado en la sociedad tradicional ante la realidad de las organizaciones, se pretende reflexionar en torno a la posible relación existente entre el ecosistema de dicha sociedad y las modalidades de organización con las que la misma se identifica mejor o adopta, de cara a la materialización de los referentes utópicos y pautas culturales que constituyen su horizonte de expectativas. Ecosistema que aquí es entendido como una totalidad estructurada, en la que están interrelacionadas dialécticamente las actuaciones organizativas que podrían denominarse como estrictamente sociales (es decir, las prácticas económico-productivas e instirucionales, así como las estrategias de carácter simbólico-legitimador encaminadas a explicar y/o justificar esas prácticas) y las características físicas y naturales del espacio o hábitat sobre el que 
tienen lugar tales actuaciones. En definitiva, dicho ecosistema implica la configuración estructurada de un entorno fisico-social específico, cuyas condiciones, en el caso de las sociedades campesinas tradicionales, son muy poco propicias para el surgimiento y desarrollo de formas de organización políticas y/o racionales instrumentales.

En el ecosistema agrario tradicional, en cierto modo, se produce una especie de adaptación pasiva por parte del campesino con respecto a su entorno, pues aquél, dadas las limitaciones técnicas que tiene, se ve obligado a acomodarse a los ritmos, ciclos y condicionantes de la naturaleza, en lo que se refiere a la cantidad de recursos alimenticios y de otro tipo que puede extraer de dicho entorno, así como a las condiciones de vida que le permite llevar la economía de subsistencia que posibilita el mismo. En cambio, en las modernas sociedades agrarias, los adelantos tecnológicos y el nivel de conocimientos científicos existente permiten un fuerte incremento de los rendimientos de los cultivos y, consiguientemente, un gran relanzamiento de la producción, a la vez que un nivel de control muy elevado sobre el medio físico-natural, lo que, a su vez, posibilita el surgimiento y desarrollo de una mentalidad colectiva basada en la adaptación transformadora y activa sobre tal medio. Todo esto hace que los ecosistemas agrarios modernos sean más adecuados para la generación y desarrollo en eilos de una mayor conciencia de las características y posibilidades de la organización político-burocrática y formal racional-instrumental.

En consonancia con lo que se acaba de decir, el retraimiento y/o desconcierto de la mentalidad campesina tradicional frente a las formas de organización política, que, a su vez, está ocasionado por motivos análogos a los de su usual inhibición en materia de innovación social y de cambios en lo económico-productivo, sería explicable, entre otras razones, como un efecto de la conciencia de adaptación pasiva al entorno que propicia el ecosistema en el que se produce y desarrolla dicha mentalidad. Así, los mismos condicionantes ecosistémicos que hacen que el campesinado tradicional tienda a inhibirse y a rechazar el cambio socioeconómico, serfan también los causantes de la actitud de aquél ante las formas de organización politica. Y ello porque, al fin y al cabo, la politica puede ser entendida, entre otros aspectos, como una estrategia tendente a la planificación y organización racional y conjuntada de la actividad humana de cara a conseguir determinados fines; en definitiva, como una forma de acción social encuadrable dentro del paradigma weberiano de racionalidad formal-instrumental medios-fnes, en el que, por lo general, se asientan las modernas organizaciones. Racionalidad cuyo desarrollo transcurrío paralelo al proceso de paulatino arraigo, en el mundo occidental, del antropocentrismo inherente al afranzamiento de la modernidad. Antropocentrismo que implicaba una visión del hombre como sujeto activo transformador del mundo. Se trata del progresivo asentamiento de una praxis (determinante/determinada de/por los adelantos tecnológicos que acompañaron su desarrollo) amparada en una mentalidad manipuladora de la realidad en general que, frente a las ataduras a las que se habia encontrado sometido el hombre hasta entonces, propugnaba la articulación racional de proyectos (a fin de cuentas, de medios instrumenta- 
les) encaminados a participar activamente en la modificación del entorno económico, político, social y físico, a romper los límites a la transformación del mundo y al desarrollo de las fuerzas productivas que imponía el mismo ${ }^{6}$. A raíz del proceso de paulatino afianzamiento de la modernidad urbana que se ha experimentado en occidente a partir del Renacimiento, en el plano políticoinstitucional se ha producido la progresiva articulación de organizaciones formales racionales instrumentales. Ejemplos de éstas son las modernas burocracias (inherentes a los procesos de centralización administrativa y de modernización del Estado), las relativas a la planificación e institucionalización de los programas y fenómenos revolucionarios modernos o, por último, el nacimiento y desarrollo de partidos políticos. La aparición de dichas organizaciones, ya se hiciera en nombre de fines moderados o más o menos extremistas y revolucionarios, se llevó a cabo, generalmente, con el fin de articular proyectos, reformistas o subversivos según los casos, tendentes a regular y/o a transformar el orden social, así como a romper las limitaciones de éste para adecuarlo a las necesidades de todos los hombres. Pero, mientras no penetraron las pautas organizativas modernas en el ámbito de la sociedad campesina tradicional, ésta siguió articulándose por cauces diferentes a los de la racionalidad formal-instrumental inherente a la política y a la burocracia. Además, dadas las limitaciones $y / 0$ alteraciones que para su mundo supuso, por lo habitual, el proceso de penetración de los patrones organizativos modernos, en muchas ocasiones se desarrolló una actitud de rechazo y de repliegue en su mismidad que no hizo más que fortalecer, al menos durante un tiempo, la mentalidad y la conciencia organizacional típicas del medio tradicional campesino (este sería, por ejemplo, el caso del carlismo).

El desempeño de la actividad política conlleva la necesidad de interiorización de unos paradigmas organizativos, cuyo desarrollo no propicia el entorno existencial y ecosistémico en el que transcurre la vida del campesinado tradicional. En cambio, el medio urbano moderno posibilita la presencia de unas mayores facilidades para la delimitación y organización racionalmente planificada del espacio. Se trata de lo que podría conceptuarse como una cierta forma de organización del hábitat, de cara a la configuración geométrica y consiguiente estructuración racional del mismo. Organización llevada a cabo mediante proyectos elaborados de acuerdo con una racionalidad instrumental medios-fines, relativamente más eficaz (dados los mejores medios técnicos de los que en este contexto se dispone) y estricta, etc., etc.. En definitiva, el ecosistema urbano presupone el desarrollo de una constelación de actividades que conjuntamente

6. Si bien la idea moderna del desarrollo ilimitado propició los grandes avances que dieron lugar a la, relarivamente buena, siruación económico-productiva actual, el hecho es que hoy nos hemos percatado de la necesidad de poner limites al desarrollo si no queremos destruir nuestro propio entorno ecológico. En este sentido, la ecología implica una cierta forma de retorno, aunque cualicativamente a otro nivel, a la originaria conciencia colectiva de acomodación a las exigencias del medio fisico-narural vigente en el mundo campesino tradicional. 
podrían conceptuarse como: estrategias instrumentales encaminadas a la planificación y/o racionalización del entorno. La mentalidad burocrático-política es inherente a una praxis organizadora de estrategias, a unos proyectos dirigidos, de alguna forma, a la racionalización del presente y a la previsión del futuro. Lo político, como lo burocrático-administrativo, encuentran su símil paradigmático y campo más propicio de actuación en el medio urbano. Desde estos presupuestos, es explicable que, incluso en el hipotético caso de que no hubiera motivos de rechazo, en general, las sociedades campesinas tradicionales, en cuyo contexto existencial todavía no han penetrado del todo las pautas culturales y las técnicas inherentes a la modernización, se sientan desconcertadas por los patrones de organización que conlleva la política y por los referentes culturales en los que se asientan las organizaciones e instituciones del medio urbano-industrial.

La política y lo urbano: marcos simbólico-paradigmáticos no fácilmente comprensibles para la mentalidad del campesinado tradicional, entre orras razones, como se ha visto, debido al entorno ecosistémico en el que aquella se genera y desarrolla. El desconocimiento o desconcierto, cuando no rechazo frontal, de los paradigmas políticos fue también, en el caso del anarquismo español, una de las principales causas del prácticamente nulo protagonismo del campesinado en los procesos sociohistóricos que condujeron a la modernización y consiguiente instauración de un Estado centralista moderno, estructurado de acuerdo con pautas organizativas de índole burocrático-política. Incluso algunos de los propios anarquistas fueron, en mayor o menor grado, conscientes de las limitaciones a las que conducía esta actitud ante las formas de organización políticas; tal es el caso, por tomar un ejemplo, de F. Carrasquer, militante e intelectual libertario en el exilio, que se expresó en los términos que seguidamente se transcriben:

[...] El pueblo español, en su proverbial aislamiento, ha perdido la visión de la política. Esta pérdida es absolutamente intolerable si se quiere formar un sistema democrático, una sociedad constructiva, justa y creadora [...]. (cit. por Álvarez Junco, 1976: 599)

\section{Bibliografía}

ÁlVAREZ JUNCO, José (1976). La ideologia politica del anarquismo español (1868-1910). Madrid: Siglo XXI editores.

Arostegui, J.; Bu.nKhorn, M.; TorRe, J. M. \& FernANdez, M. (1985). "Los Carlistas". Cuadernos de Historia 16, núm. 280.

Barragán, A.; GonzAllez, M. \& SeVILla, E. (1985). "Revueltas campesinas en Andalucían. Cuadernos de Historia 16, núm. 294.

Coleman, James (1990). Foundations of social theory. Cambridge: Belknap Press of Harvard University Press.

DIÁ DEL MoRAl, Juan (1979). Historia de las agitaciones campesinas andaluzas. Madrid: Alianza Editorial. 
ENTRENA DURÁN, Francisco (1994a). "Cultura política y racionalidad formal-instrumental en la acción social del nuevo sindicalismo agrario del sur de Españan. Texto inédito del paper presentado pot el autor al XIII Congreso Mundial de Sociología. Bielefel (Alemania), julio de 1994.

- (1994b). "El SOC: un caso de reacción campesina ante la modernización rural». Revista de Fomento Social, núm. 194, vol. 49, abril-junio 1994. Córdoba: ETEA.

FUENTE, Gloria de la (1991). Las organizaciones agrarias españolas. Madrid: Instituto de Estudios Económicos. Colección Tablero.

HoBSBAWM, Eric J. (1974). Rebeldes primitivos. Barcelona: Ariel.

- (1978). «Bandolerismo Social». En Henry A. LANDSBerger (ed.). Rebelión campesina y cambio social. Barcelona: Grijalbo.

MARX, Karl (sin fecha de edición). El dieciocho brumario de Luis Bonaparte. Moscú: Ed. Progreso.

MOORE BARRINGTON (1976). Los origenes sociales de la dictadura y de la democracia. Barcelona: Ed. Península.

Moyano ESTRADA, Eduardo (1992). "Representación de intereses en la agricultura andałuza" (documento de trabajo). Andalucía, Córdoba: Consejo Superior de Investigaciones Cientfficas, Instituto de Estudios Sociales Avanzados.

Pérez Yruela, Manuel (1990). "La sociedad rural". En España. sociedad y politica, tomo I, edición dirigida por Salvador Giner. Madrid: Espasa-Calpe.

«Progresar... ¿es no comer? Alrernativa del SOC a la acrual siruación del campo andaluz" (1979).

Tierra y Libertad, se trata del periódico del SOC, del que se han analizado distintos números, comprendidos entre finales de los setenta y principios de los ochenta.

Tiliy, Charles (1978). From Mobilization to Revolution. Reading, Mass.: AddisonWesley.

Weber, Max (1979). Economía y Sociedad. México: Fondo de Cultura Económica.

WOLF, Eric R. (1979). "Las rebeliones campesinas". En Campesinos y sociedades campesinas, de Teodor Shavin. Mexxico: Fondo de Cultura Económica. El tema de este texto de Wolf está más ampliamenre desarrollado en su obra Las luchas campesinas del siglo xx. México: Siglo XXI, 1979. 